\title{
Electronic-Acquisition Software's Key Factors And Subsequent Impact: Points Of View From User's
}

\author{
Rehan Khalique, Muhammad Asim, and Salman Manzoor
}

\begin{abstract}
Electronic-Acquisition Software's implies the usage of data and correspondence advances utilizing the Internet to do all phases of the Procurement procedure. The greater part of the organizations execute this new arrangement of Electronic-Acquisition Software's and they are succeeding while many come up short. This examination was completed on surveying Electronic-Acquisition Software's achievement factors among some Steel Companies of Pakistan. The target of the examination decides the achievement factors impacting the accomplishment of Electronic-Acquisition. This investigation included a semi-organized meeting from the acquirement administrators of chose associations for the distinguishing proof of accomplishment factors in their associations. Expressive methodology was embraced to locate the significant components that impact the accomplishment of Electronic-Acquisition Software's , from eight organizations a sample size of (150) respondents took an interest for the quantitative information assortment through a study survey. SPSSv22 is utilized to break down the gathered information and different examination are performed. It is uncovered from the examination that the entirety of the associations have embraced Electronic-Acquisition Software's with rehearses like e-sourcing, notice and offering on the web offer accommodation and proposition accommodation however because of uneducated market and feeling awkward in utilizing new framework at provider/merchant end a portion of the practices are not begun like e-installments.
\end{abstract}

Index Terms-DeLone \& Mclean; Electronic-Acquisition Software's; ISs (Information System Success); T.A.M.

\section{INTRODUCTION}

Reference [64]-[68]-[67]-[70] shows, Electronic trade, regularly alluded to as online business cannot move forward by excluding the assist of integrated-authoritative framework. In such hierarchical framework empowers an association to trade data and direct dealing by electronic means. What's more, improvement in data innovation, particularly web innovation, has improved the procedure and diminished the expenses of leading business exchanges by electronic means among associations. Hence due to end to end utilization of web based innovations has unlocked the trade opportunities worldwide.

Reference [55]-[57]-[60] shows, several nations are now realizing significance in utilizing data and correspondence innovation in developing a productive. Reference [58] shows, straight forward administration. Reference [50] shows, the belief about ICT, that it has prompted change in outlook through coming of instance organize insight,' uniting trade, management, and individual regarding which the administration label e-management. Subsequently utilization and information on ICT is quickly extended. Such addition is replicated during implementation of eacquirement. The superior cooperation devices among management and the confidential element. Electronicacquirement software's is a type of web based business execution, has numerous definitions. Reference [19] shows,

electronic-acquirement software's alludes for utilization based on a coordinated correspondence framework, which is generally electronic, to perform most or the entirety of the buy procedure. In This Study on endeavors to survey the Electronic-Acquisition Software's achievement factors in Steel Industries in Pakistan. The primary motivation behind this investigation is to see how the different elements assume their job in making Electronic-Acquisition Software's innovation a triumph for the business.

\section{HYPOTHETICAL SCENERY}

Electronic-Acquisition Software's is characterized as a function which buck up indirect expenditure via giving Individually-administration answers in favor of mentioning , requesting merchandise with enterprises regarding normal client, whom definitely is not an expert ElectronicAcquisition Software user. Be that as it may, different meanings of electronic-acquisition software's which are present. Some researchers characterize electronicacquisition software's in a way for incorporation, the executives, mechanization, streamlining, and strengthening of the acquirement procedure of an association through gear, innovation, hardware, and electronic applications.

\section{DELONE AND MCLEAN INFORMATION SYSTEM SUCCESS MODEL}

Reference [21]-[22]-[44]-[48]-[63]-[78]-[79] shows various investigations which directed for recognizing elements which add in accomplishment regarding data frameworks (I.S's). Reference [21]-[22]-[44]-[48]-[63]-[78]-[79] shows idea for accomplishment components in I.S's which are all the additional completely incorporated, bringing about the presentation of a total scientific classification. The scientific classification proposed five measurements or primary classes:

The nature of the framework, that centers around the ideal attributes in reference with $I S$.

The nature of data, along with attention on item data in respect of wanted qualities, for example, precision, importance of data, and practicality

Handling with client fulfillment, that investigates regarding associations among the beneficiary, item data/clients and the one who makes the decision. 
The sway on people, whom examine the impact with reference to item's data on the executives choices

The sway on the association, that examine impact of item data on presentation of the association.

\section{HYPOTHESIS BUILDING}

Features of Electronic-Acquisition Software's System, effects confidence along with userClient need fulfillment

Electronic-Acquisition Software are viewed as a type of I.S's. Reference [21]-[22]-[44]-[48]-[63]-[78]-[79] shows amendments in IS achievement structure which contain various fundamental elements of value, to be specific Electronic-Acquisition System framework Features, Outputdata quality, and service level. The measurements ought to be estimated, as independently and altogether, this influences client's need fulfillment. In light of above points, we figured theories as pursues:

Hyp. \#01: Electronic-Acquisition Software's

Data credibility effect Customer Need fulfillment.

Hyp. \#02: Electronic-Acquisition Software's

system performance effect Customer Need fulfillment.

Hyp. \#03: Electronic-Acquisition Software's extensiveness effects Customer Need fulfillment.

service

Other than the feature and substance in ElectronicAcquisition Software's system, utilization Along with Client's requirement fulfillment influences directly to the achievements of Electronic-Acquisition. The concern of belief is additionally a determinant. Reference [11]-[12][15]-[16]-[17]-[18]-[29]-[30] shows, belief or trust is impression for unwavering quality including trustworthiness regarding framework.

User should have the option of confide on legislature along with innovation. Along these lines, confidence in innovation remains obvious to move forward with innovation, that is in this situation points towards Electronic-Acquisition Software's framework. Surely, confidence is a significant element for administrating key features in respect of electronic-taxpayer driven organizations. hence, accordingly we conceive below hypothesis:

\section{Hyp. \#04: Electronic-Acquisition Software's Data} interpretation influence confidence.

Hyp. \#05: Electronic-Acquisition Software's frame work performance influence confidence.

Hyp. \#06: Electronic-Acquisition Software's service extensiveness influence confidence.

Link of guidelines, past incident, and the board of Directors backing to customer fulfillment plus confidence

Reference [31]-[74]-[75]-[76]-[77] shows, regarding T.O.E.
Structure that is regarding technology, organization, and environment. This suggest for an organization's choice in receiving development relies on variables in different areas, to be specific innovative, authoritative, and natural. Government guidelines are frequently viewed as a viewpoint wherein the administration's administrative condition is viewed as a risk, because of the utilization of institutionalized procedures and the execution of guidelines [5]-[13]. A few examinations on data innovation reception refer to the positive effect of a domain with a significant level of guidelines, particularly in less-created nations since this build's confidence. In this manner, guidelines suggested by governing body regarding electronicacquisition software's expands confidence in ElectronicAcquisition Software's framework. In this way, we place the associated hypothesis as below:

Hyp. \#07: Law of Land influence confidence in ElectronicAcquisition Software's Framework.

Affirmative effect of such appropriation regarding such guidelines influences client's need fulfillment. Client's need fulfillment is actually inclination as well as conduct in the direction of various components in specific circumstance. Way forward as in [1]-[8]-[9], idea provides guidelines are in addition an integral part influencing client fulfillment. This is known as 'the sentiment of control'. It is client's attention for individual authority in other words absence in capacity regarding teach, guide \& overwhelm the progression, adjust along with implementation for I.S's as in [4]. Consequently, the associated Hypothesis will be:

Hyp. \#08: Management guidelines influence client's needs fulfillment in utilizing electronic-acquisition software.

The innovation acknowledgment model (T.A.M) is the system for assessing client(User of Software) acknowledgment of I.S's. Affirmation of advancement itself isn't simply influenced by the specific perspectives yet what's more the social points. Prior knowledge, the single exterior aspect employed for the learning that is verified during quite a lot of experimental learning.

Past practice of Customer in utilizing PCs and comparable softwares. Reference [5]-[7]-[25]-[26]-[27]-[28] Shows, past practice give awareness to the Software operator regarding qualities and shortcomings in electronicacquisition software's framework. An absence in aptitude utilizing I.S's along with online software features is capable to make an operator experience shift in negative paradigm. Such wonders regularly allude and can be seen written to be 'vanished within hyperspace,' that happens as soon as utilization of I.S's goes less significant to a person. In this case client doesn't have a clue how to return to a common spot. Clients who lose their course would experience I.S'sues catching basic data, and they will keep on having sentiments of perplexity. Reference [67] shows, to obstruct the knowledge of the IS. Consequently, the hypothesis will be as following:

Hyp. \#09: Encounters of past suppliers influence client (operator) need fulfillment with regards to Electronic-Acquisition Software. 
There is high risk involve in every Transaction through software that route through online channel. Past incident shows tremendous impact on client's conduct after wards. Reference [14]-[32]-[33]-[34]-[36]-[39] shows, clients with regards to web based shopping will assess their past shopping encounters identified with view of item data, types of installment, conveyance understandings, administrations offered, the dangers related with protection, safety, individualization, route and so on. Along these lines, the formulated hypothesis will be as under

Hyp. \#10:Encounters of past user's influences confidence in Electronic-Acquisition Software system.

The estimation regarding authoritative help is readily divisible in a few categories: Starting with the one which suggests in supporting progression in software's working platform. The other is broad facilitation by administration in the form of allocating the resources as per required. Reference [41]-[42]-[43]-[49]-[51]-[52]-[53]-[54]-[56] shows, The requirement for hierarchical help as far as Electronic-Acquisition Software System is concerned, which originated an important barrier for ElectronicAcquisition Software's treatment method in Australia urban committee is not financial advantage, however trouble was for incorporation of Electronic-Acquisition's Software's system into the software which handles committees financial matters. Help by firm influence employee's response for related job, together with need fulfillment along with constructive behavior. As a Supplement, help via proprietor firm who provided the Electronic-acquisition software create esteem in the views of Software users.Referecne [7] shows, that after sales service provider firms develop trust which is actually a key factor in obtaining future gains. Beside this position, the accompanying hypothesis will be as follow:

Hyp. \#11: Back-Up Service by the firms influence client need fulfillment in Electronic-Acquisition Software's scenario.

Hyp. \#12: Back-Up Service by the firms influence client confidence in Electronic-Acquisition Software's scenario.

Client need fulfillment Influences confidence \& apparent advantages.

Reference [80]-[81] shows, during examination advantages weren't estimated legitimately with the goal that lone the advantages apparent by the client (Assumed benefits) are estimated. The apparent advantages of this exploration are the normal straightforwardness of acquirement through Electronic-Acquisition Software's related to the concealment of the normal advantages of ElectronicAcquisition Software's .Thus, following hypothesis we form:

Hyp. \#13: Client need fulfillment influences apparent advantages in frame work of Electronic-Acquisition software systems.

Reference [69]-[65]-[66]-[68]-[69] shows, confidence generate significance while granting relative advantages achieved by frequent communication with proficient back up support givers which are solution focused attitude and compassionate as well. This is how the back up support diminish improbability supposed in mind of the client that assist client to set up reliable pre-assumption for backup support. Consequently the drawn hypothesis is as follow:

Hyp. \#14: Confidence influences supposed advantages associated with Electronic-Acquisition software's systems.

Client's need fulfillment is too affected due to confidence. Reference [37]-[38]-61]-[62]-[63]-[64] shows, the clients of online applications regularly maintain a strategic distance from the virtual stores which can be esteemed deceitful. confidence often energizes client conduct as client fulfillment that will bring about recurrent buys or alleged client dedication. consequently, my final hypothesis is is as follow:

\section{Hyp. \#15: Confidence influence Client need fulfillment} towards Electronic-Acquisition software system.

Below here, representation for determining achievement by Electronic-Acquisition Software's framework, founded over preceding imagery regarding Key elements of ElectronicAcquisition Software's. The idea expected to yield the winning structure regarding Electronic-Acquisition Software's frame works.

Hypothesis investigation structure

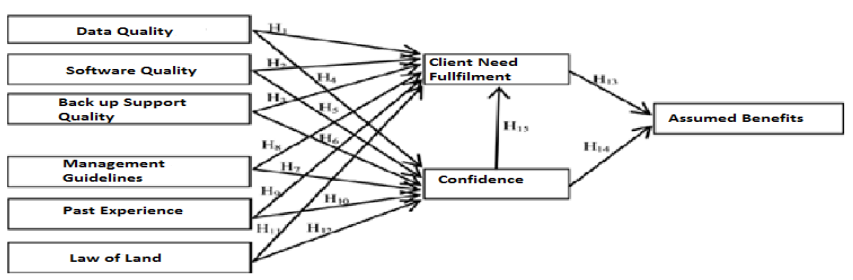

\section{RESEARCH PROCEDURE}

The assessment utilizes magnitude based investigation sense.

For checking the hypothesis also for notifying the connections between variables. The methodology uses information assortment techniques, for example, studies and trials with measurable investigation. The figures are acquire by survey by Five point Likert scale: Strongly Disagree, Disagree, Neutral, Agree, and Strongly Agree. Poll is picked in light of the fact that the potential respondents were spread generally all through Steel industry; subsequently, a survey is the most proper strategy for the information assortment of this examination. The survey strategy has a few focal points, for example, its minimal effort and it offers obscurity since it doesn't expect up close and personal gatherings.

\section{SAMPLING METHOD}

For decreasing favoritism along with implementing model through additional gauge on each D.Vs the lot volume for thirty three create adequate focused elucidation. Though the lot for 100 might suitable in developing adequate more 
focused elucidation.up till now further debate so as to maximize probability evaluation method proceeds reasonably legitimate outcome by way of lot magnitude 33 Nos. however Such Lot magnitude is un-suggested. The lot magnitude for up to 200 suggested for applying ML procedure..

\section{INVESTIGATION TOOLS}

The Investigation tools formed through constructing indicator acquire by investigation framework which include following aspect: information feature, structure feature, administration feature, law of land guidelines, knowledge, hierarchical help, client fulfillment, confidence including presume payback

\section{Investigation tool}

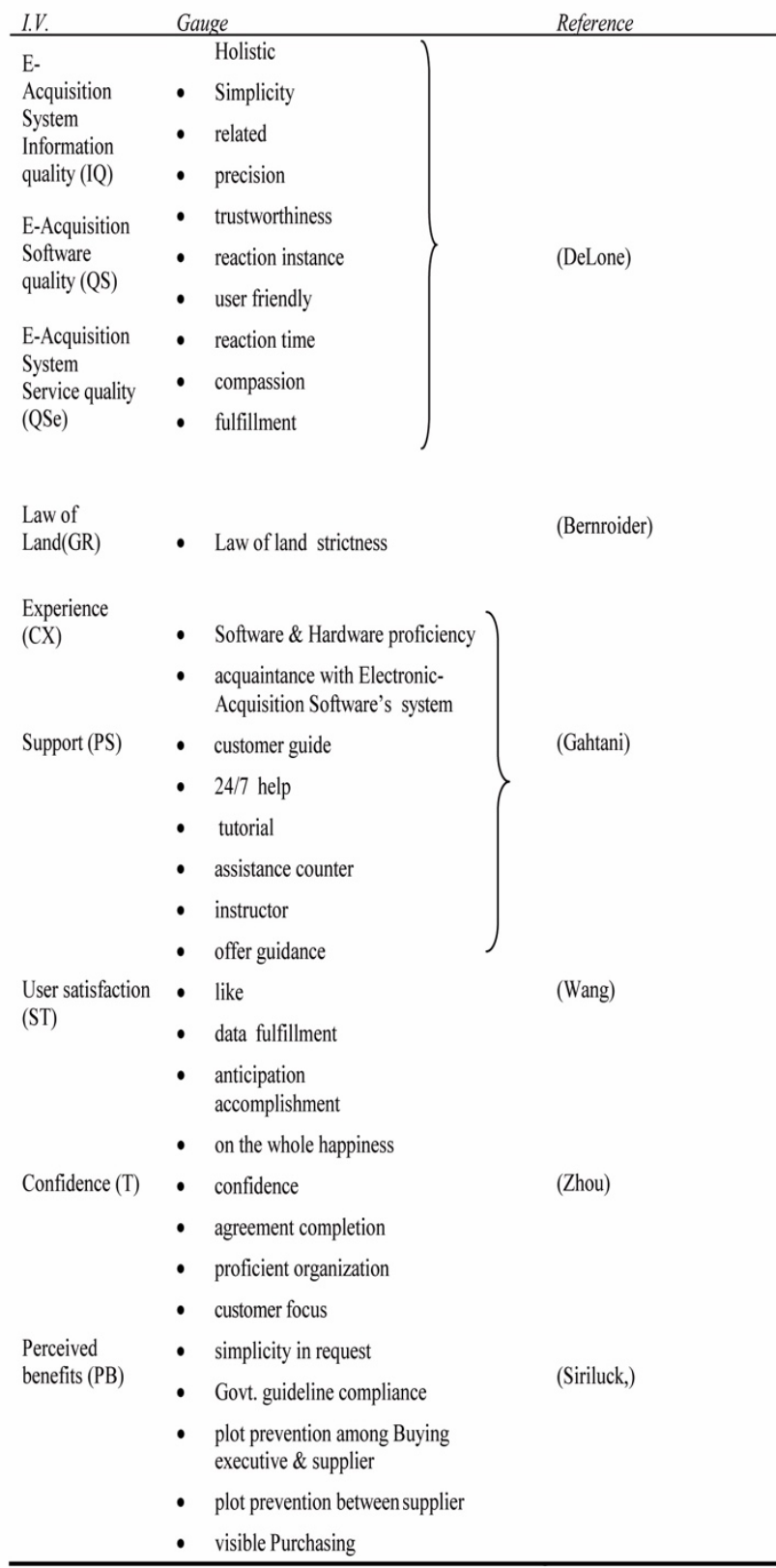

\section{RESULT}

With our information assortment organization, we have got legitimate total respondents 150 nos. who rounded out the poll completely. So as to figure the investigation frame work.

According to expert it is important to test the estimation frame work pursued by the structural frame work. The frame work structure shows how hypothetically a framework can be formed by marked variable.

To begin with, let's depict the socioeconomics for the Questionnaire answerers.

\section{A. Questionnaire answerer's socioeconomics}

Questionnaire answerers in respect to exploration were to a great extent organization workers with involvement in acquirement by Electronic-Acquisition Software's framework. Most of Questionnaire answerers (63\%) reflects matured more than 25 in age along Graduation certification. the majority answerers (69\%) employed in present organization over 3 years.

Greater part had understanding in utilizing the ElectronicAcquisition Software's framework in a period within 5 year. Itemized socioeconomics for Questionnaire answerers for exploration can be seen Below.

\section{QUESTIONNAIRE ANSWERER'S SOCIOECONOMICS TABLE}

\begin{tabular}{|c|c|c|}
\hline Description & Marking & Proportion $(\%)$ \\
\hline \multirow[t]{5}{*}{ Age } & $<=20$ & 1 \\
\hline & $21-30$ & 5 \\
\hline & $31-40$ & 6 \\
\hline & $41-50$ & 12 \\
\hline & $>50$ & 09 \\
\hline \multirow[t]{3}{*}{ Education } & Bachelor & 65 \\
\hline & Master & 4 \\
\hline & Other & 31 \\
\hline \multirow{3}{*}{$\begin{array}{l}\text { Working experience } \\
\text { (year) }\end{array}$} & $<3$ & 21 \\
\hline & $4-5$ & 7 \\
\hline & $>5$ & 72 \\
\hline \multirow{3}{*}{$\begin{array}{l}\text { Electronic- } \\
\text { Acquisition } \\
\text { Software's } \\
\text { Software's } \\
\text { experience (year) }\end{array}$} & $<=2$ & 44 \\
\hline & $3-4$ & 52 \\
\hline & $>5$ & 4 \\
\hline
\end{tabular}

\section{B. Structure of Estimation}

For analysis, plus approving estimation structure for exploring the examination we utilized SPSS programming. Preliminary test, authenticity and steady quality were directed through assessing authenticity to utilize T.Value and institutionalized stacking aspect. Tabulation below reflects the entire markers breezed through assessment in authenticity as the entire have T.Value $\geq 1.97$ with institutionalized stacking aspect estimation $\geq 0.51$. In order for assessing steady quality, amalgamate score dependability (CR.) difference extricated (VE.) magnitude were acquired. Every single factor likewise completed the evaluation for steady quality since every marker carries an evaluation of combination dependability (CR.) $\geq 0.69$ with difference removed (VE.) $\geq 0.55$ 


\begin{tabular}{|c|c|c|c|c|}
\hline Indicators & L. aspect & T.Value & CR. & VE. \\
\hline QD & & & 0.911 & 0.673 \\
\hline QD1 & 0.69 & 8.91 & & \\
\hline QD2 & 0.90 & 11.37 & & \\
\hline QD3 & 0.89 & 14.06 & & \\
\hline QD4 & 0.81 & 9.99 & & \\
\hline QD5 & 0.79 & 12.07 & & \\
\hline QS & & & 0.846 & 0.582 \\
\hline QS1 & 0.69 & 9.18 & & \\
\hline QS2 & 0.70 & 7.73 & & \\
\hline QS3 & 0.86 & 11.58 & & \\
\hline QS4 & 0.79 & 12.17 & & \\
\hline QSe & & & 0.905 & 0.761 \\
\hline QSe1 & 0.86 & 13.46 & & \\
\hline QSe2 & 0.89 & 17.57 & & \\
\hline QSe3 & 0.79 & 11.29 & & \\
\hline GR & & & 0.738 & 0.585 \\
\hline GR1 & 0.80 & 8.51 & & \\
\hline GR2 & 0.81 & 8.66 & & \\
\hline $\mathrm{CX}$ & & & 0.740 & 0.582 \\
\hline CX1 & 0.69 & 8.74 & & \\
\hline $\mathrm{CX} 2$ & 0.81 & 8.71 & & \\
\hline PS & & & 0.907 & 0.623 \\
\hline PS1 & 0.70 & 9.77 & & \\
\hline PS2 & 0.69 & 10.01 & & \\
\hline PS3 & 0.70 & 7.69 & & \\
\hline PS4 & 0.79 & 12.19 & & \\
\hline PS5 & 0.89 & 16.73 & & \\
\hline PS6 & 0.90 & 13.87 & & \\
\hline $\mathrm{ST}$ & & & 0.884 & 0.659 \\
\hline ST1 & 0.71 & 8.86 & & \\
\hline ST2 & 0.79 & 11.91 & & \\
\hline ST3 & 0.89 & 14.89 & & \\
\hline ST4 & 0.79 & 12.83 & & \\
\hline $\mathrm{T}$ & & & 0.922 & 0.749 \\
\hline $\mathrm{T} 1$ & 0.79 & 13.94 & & \\
\hline $\mathrm{T} 2$ & 0.89 & 15.63 & & \\
\hline T3 & 0.89 & 15.29 & & \\
\hline $\mathrm{T} 4$ & 0.79 & 11.86 & & \\
\hline PB & & & 0.869 & 0.581 \\
\hline PB1 & 0.49 & 6.12 & & \\
\hline PB2 & 0.70 & 9.58 & & \\
\hline PB3 & 0.89 & 17.17 & & \\
\hline PB4 & 0.89 & 21.52 & & \\
\hline PB5 & 0.70 & 9.96 & & \\
\hline
\end{tabular}

To test the sensibility of the model, this investigation used 11 all around propriety analysis condition, which are root mean square error of gauge "R.M.S.E.A.", root mean square waiting "R.M.R.", organized R.M.R., uprightness of-fit rundown "G.F.I.", non-normed fit record "N.N.F.I.", normed fit document "N.F.I.", relative fit document "R.F.I.", consistent fit record "I.F.I.", close to fit rundown "C.F.I.", stingy normed fit record "P.N.F.I.", and normed chi-square. In Table, all of the criteria are at the most distant point level of affirmation, showing that the estimation model exhibited a strong match to the examination data. It will in general be contemplated that the estimation model indicated the authenticity, faithful quality, and likeness as agreeably extraordinary.

TABULATION GOODNESS FIT TEST

\begin{tabular}{lcc}
\multicolumn{3}{c}{ TABULATION GOODNESS FIT TEST } \\
\hline Decisive factor & Limit of acceptance & End result \\
\hline R.M.S.E.A. $\leq$ & 0.09 & 0.019 \\
S.R.M.R $\geq$. & $0.06<$ S.R.M.R. $\leq 0.11$ & 0.079 \\
G.F.I. $\geq$ & 0.85 & 0.79 \\
N.N.F.I. $\geq$ & 0.85 & 0.98 \\
N.F.I. $\geq$ & 0.85 & 0.95 \\
R.F.I. $\geq$ & 0.85 & 0.99
\end{tabular}

$\begin{array}{lcc}\text { I.F.I. } \geq & 0.85 & 0.97 \\ \text { C.F.I. } \geq & 0.85 & 0.98 \\ \text { P.N.F.I. } \geq & \text { As max possible } & 0.98 \\ \text { Chi-square } & 2 & 1.20 \\ \left(X^{2} / \text { df }\right)< & & \end{array}$

\section{Structural model}

For Wake of leading the appropriateness trial of the estimation model, the investigation of causal connections continued by taking a gander on the basis of the T.value plus coefficient of assurance i.e. R2. A T.value $\geq 1.97$ demonstrates regarding critical connecting correlation. Below Tabulation reflects the T.value related to every theory with respective acceptance/ redundancy.

TABULATION FOR RESULTS OF STRUCTURAL MODEL TEST

\begin{tabular}{|c|c|c|}
\hline Path & T. Value & Conclusion \\
\hline Hyp.\#01: IQ $\rightarrow$ ST & 1.51 & Redundant \\
\hline Hyp.\#02: QS $\rightarrow$ ST & 1.99 & Ok \\
\hline Hyp.\#03: QSe $\rightarrow$ ST & 0.98 & Redundant \\
\hline Hyp.\#04: IQ $\rightarrow$ T & 0.35 & Redundant \\
\hline Hyp.\#05: QS $\rightarrow$ T & 1.98 & $\mathrm{OK}$ \\
\hline Hyp.\#06: QSe $\rightarrow$ T & 2.00 & OK \\
\hline Hyp.\#07: GR $\rightarrow$ T & -0.51 & Redundant \\
\hline Hyp.\#08: GR $\rightarrow$ ST & 2.95 & $\mathrm{OK}$ \\
\hline Hyp.\#09: CX $\rightarrow$ ST & -0.64 & Redundant \\
\hline Hyp.\#10: CX $\rightarrow$ T & 0.50 & Redundant \\
\hline Hyp.\#11: PS $\rightarrow$ ST & 0.60 & Redundant \\
\hline Hyp.\#12: PS $\rightarrow$ T & 1.59 & Redundant \\
\hline Hyp.\#13: ST $\rightarrow$ PB & 0.68 & Redundant \\
\hline Hyp.\#14: T $\rightarrow$ PB & 3.03 & $\mathrm{OK}$ \\
\hline Hyp.\#15: T $\rightarrow$ ST & 2.99 & $\mathrm{OK}$ \\
\hline
\end{tabular}

In light of Tabulation appeared above, data quality don't put influence over client need fulfillment \& confidence; in this way, Hyp.\#01 along with Hyp.\#04 become redundant. Framework's feature has effect on client fulfillment and confidence; hence, Hyp.\#02 along with Hyp.\#05 become OK. Impact of services qualities in respect of client's need fulfillment isn't critical, where as this influences confidence; thus Hyp.\#03 Redundant, Hyp.\#06 OK. Law of Land don’t influence client's need fulfillment, while Management Guidelines influence client's need fulfillment accordingly, Hyp.\#07 Redundant, however Hyp\#08 OK. Past know-how in case of suppliers also for back-up support providers backing don't influence client's need fulfillment along with confidence; thus Hyp.\#09,10,11,16 redundant. Confidence influences client's need fulfillment also on to Assumed advantages; in this manner, Hyp.\#14,15 OK. In any case, client fulfillment doesn't influence the apparent advantages; consequently Hyp.\#13 redundant. As per the discoveries, just six theories acknowledged in this exploration, they finally is Hyp. $\# 01,05,06,08,14,15$.

\section{DEBATE AND IMPLICATION}

\section{A. Debate}

In light of above analysis, we portray further descriptively the impact due to every autonomous factor which remains in the exploration model as contrasted and the consequences of different investigations. 
Electronic-Acquisition Software's feature \& intensity on Client's need fulfillment and confidence of User

Outcomes indicated solitary framework feature of software impact's fulfillment and confidence. Administration features affects confidence, however not on fulfillment. Data quality demonstrated to have no effect on either fulfillment or confidence.

From these outcomes, apparently the nature of the data doesn't influence client fulfillment and confidence. Data Nature appeared in influencing client fulfillment. Reference [2]-[3]-[35]-[40]-[45] shows, the nature of data influences the apparent incentive. This distinction might happen because of the various attributes among frameworks of electronic-acquisition. Consequently, the more noteworthy the data disappointment, the elevation in depressed authentication definitely surface bringing about lesser fulfillment. talk with gathering following the quantified examination, the answerers of Survey questionnaire think about a few time they still questioned the administration's duty to utilizing the ElectronicAcquisition Software's framework genuinely. the answerers of Survey questionnaire think as a great deal in rspt of communication by the legislature to clients at the back of Electronic-Acquisition Software's framework.

Excellence, the main quality angle which influences fulfillment and confidence inside electronic-acquisition framework. In this manner, framework unwavering quality, the speed of reaction, convenience, and a decent and straightforward UI affect the fulfillment along with confidence in clients of Electronic-Acquisition Software's frame work.Great framework quality enables clients to get to the electronic-acquisition framework easily, with the goal that client's need fulfillment and confidence increment.

Un-technical aspects along with respective consequent pressure on Client's need fulfillment as well as on confidence

Un-technical components considered during examination comprises guidelines, knowledge, and backing by association.

The examination, guidelines demonstrated in order for influencing client fulfillment. These outcomes are steady with inquire about directed by as per Zhu. The investigation expressed some guidelines which positively affect creating nations, which will, thus, make client fulfillment. In any case, guidelines are not appeared to have an impact on confidence as clients feel that regardless of whether guidelines on e-acquirement are set up, the possibility for conspiracy between the administration clients yet remains. Familiarity which demonstrated neither influence client fulfillment nor confidence. Reference [67]-[72]-[73]-[82][83] shows, The outcome isn't predictable with the examination, which demonstrated regarding past knowledge affected client fulfillment. This is on the grounds that, if a client doesn't have past understanding, this can prompt perplexity and bewilderment for the client, bringing about a terrible encounter. Thus, this awful experience can influence client fulfillment. Moreover, support from the executives was additionally demonstrated not to influence client fulfillment and confidence. Backing as documentation and preparing may assist clients with acing the Electronic-Acquisition Software's framework. Be that as it may, it can't make the clients fulfilled and receive confidence with respect to Electronic-Acquisition Software's framework, clients should understand regarding administration happy or not for live up to the desires for conveying a straightforward framework.

\section{B. Summary of findings}

Below tabulation reflects synopsis regarding aggregate, straight along with circuitous impacts among free along with ward factors. Confidence electronic-acquisition software systems frameworks act as a significant and progressively prevailing job for the betterment of fine administration through suppliers related to merchandise/administrations. This can be conceivable, regardless of whether the clients show them selves happy by way of Electronic-Acquisition Software's framework it will not really get better the view of fine administration. It implies that administration must think about how to create client confidence, particularly among suppliers of products/administrations, in leading exchanges utilizing the Electronic-Acquisition Software's framework. Notwithstanding, this doesn't imply that client fulfillment doesn't assume a job in improving the apparent advantages, as client fulfillment, confidence, and saw advantages of good administration are integral yet various develops. Confidence in the e-acquirement framework is incompletely interceded through client fulfillment, that has effect over the apparent advantages of fine administration.Straight, not direct, overall result which super seed apparent advantages

\begin{tabular}{|c|c|c|c|c|c|c|c|c|}
\hline & \multicolumn{3}{|c|}{ Straight } & \multicolumn{2}{|c|}{ Not direct effect } & \multicolumn{3}{|c|}{$\begin{array}{c}\text { Overall } \\
\text { result }\end{array}$} \\
\hline & ST & $\mathrm{T}$ & PB & ST & $\mathrm{T} \mathrm{PB}$ & ST & $\mathrm{T}$ & $\mathrm{PB}$ \\
\hline QD & -0.30 & -0.05 & & -0.03 & -0.04 & -0.32 & -0.05 & -0.04 \\
\hline QS & 0.52 & 0.43 & & 0.21 & 0.30 & 0.72 & 0.43 & 0.30 \\
\hline QSe & 0.14 & 0.24 & & 0.12 & 0.16 & 0.26 & 0.24 & 0.16 \\
\hline GR & 0.05 & 0.33 & & 0.16 & 0.22 & 0.21 & 0.33 & 0.22 \\
\hline $\mathrm{CX}$ & 0.05 & -0.04 & & -0.02 & -0.02 & 0.04 & -0.04 & -0.02 \\
\hline PS & 0.04 & 0.11 & & 0.05 & 0.07 & 0.09 & 0.11 & 0.07 \\
\hline ST & & & 0.02 & & & & & 0.02 \\
\hline $\mathrm{T}$ & 0.49 & & 0.65 & & 0.01 & 0.49 & & 0.66 \\
\hline
\end{tabular}

The information preparing with regards to the eacquirement framework demonstrated that the complete impact of the nature of the framework on client fulfillment and confidence is more predominant than the other five measurements, to be specific nature of administration, nature of data, guidelines, experience, and backing. This implies Electronic-Acquisition Software's Software's framework designers should give more consideration to improving the nature of the framework. This strength was trailed by guidelines and nature of administration. It tends to be said that the confidence of the clients of products/benefits in the e-acquirement framework happens as soon as the concerned experience happy due to nature of framework, administrations, with guidelines.

Influence due to data features, knowledge, and backing 
aren't critical for client fulfillment and confidence. Truth be told, clients were commonly happy regarding data features which showed by the majority of respondents answered 4 or 'concur,' up till now clients were less happy by means of Electronic-Acquisition Software's framework generally speaking.

After effects associated with the investigation demonstrate significance in respect regarding utilization of numerous measurements for surveying accomplishments by electronic-acquisition framework. Data features, framework feature, and administration feature positioning is on framework advancement stage, though client fulfillment, confidence along with assumed advantages positioning is on viability impact stage. In the interim, guidelines, past experience, and backing are outer variables [12]-[15]-[20][23]-[24].

\section{Implications}

As far as the theoretical contribution, this examination will have a beneficial outcome on giving a more clear and more extensive comprehension about estimating the achievement of I.S's, particularly online exchange frameworks in the administration. Reference [21]-[22]-[44]-[48]-[63] shows IS achievement model just thinks about innovative variables (means framework feature, data feature along with administration feature)in order to gauge the accomplishment of I.S's, while outer elements likewise conceivably impact accomplishment of IS, for example, guidelines, previous knowledge, authoritative help, etc, particularly for I.S's inside the administration setting. This exploration demonstrated the significance of outside components, especially government guideline for motivating the achievement of application associated with electronic-government. The outcome with respect to government guidelines affirms Mohammed, he noted regarding safety with legally recognized situation mainly are the aspects identified with expectation of S.M.E's in order to build the use of e-acquirement. Furthermore, the outer aspect specifically administration help remains in top 5 basic achievement aspect of Electronic-Acquisition Software's selection on behalf of enormous size fabricating companies of Nairobi. Additionally the planned framework likewise affirms that confidence is most significant factor. The majority of researches concentrated inward along with resident points of view in estimating the achievement of egovernment applications. Subsequently, this exploration can fill this hole.

Before business contemplations and innovation, setting up the legitimate/administrative structure is the initial phase in Procurement change. Additionally, the administration should build supervision of the Electronic-Acquisition Software's usage.

\section{CONCLUSION, LIMITATIONS AND FUTURE WORK}

\section{A. Conclusion}

In light of information assessment, as per the target of this investigation, it very well may be inferred regarding components which impact on achievement of ElectronicAcquisition Software's frameworks can be distinguished as framework feature, administration feature, guidelines including confidence regarding Electronic-Acquisition Software's applications. Such elements demonstrated in a manner for impacting the impression of straightforwardness related to electronic-acquirement software's clients. Confidence in electronic-acquisition framework is consider to be the most prevailing element for making observation's straightforwardness. Confidence always dominatingly impacted due to framework nature in Electronic-Acquisition Software's framework. Subsequent aspect influencing confidence are guidelines encompassing the utilization in case of Electronic-Acquisition Software's framework. The following variable is the nature of administration. Additionally, in spite of the fact that clients were fulfilled when utilizing the Electronic-Acquisition Software's framework, it didn't prompt the clients' apparent straightforwardness. The view of straightforwardness in this investigation is related with acquirement straightforwardness which in the course of ElectronicAcquisition Software's as a straightforward Procurement procedure, and Procurement as per defined principles. The point which is not tend in current examination is probability of extortion among supplier and management. Further the non-attendance regarding nepotism among clients and the observation that e-acquisition software system expected in making a perfect procedure. Apparent straightforwardness in this exploration was exclusively impacted by confidence in Electronic-Acquisition Software's frameworks.

\section{B. Boundaries}

The examination comprise of supplementary confinements. To begin with, we don't unequivocally recognize the sorts of Electronic-Acquisition Software's regarding the measure of assets and kinds of products/administrations sold in our examination model. Future investigations can look at these elements in more prominent detail to check whether a connection among such components with degree of open straightforwardness. In Supplement to the above the investigation depends upon impression of single answerer from every organization. It will prompt some specific predisposition for mirroring genuine circumstance for examination. To Carry out supplementary research technically this is better to arrange direct meetings from couple of answerers for the purpose to triangulate the aftereffects related with the examination.

\section{Potential Gaps}

For gauging accomplishment of Electronic-Acquisition software's framework the client's point of view for products/administrations, analysts can allude to the elements that impact the achievement of e-acquirement applications, for example, those created in this examination. Elements not demonstrated huge in this examination can likewise be utilized as a kind of perspective for estimating the accomplishment of Electronic-Acquisition, to such an extent for further study, such elements might critical to influence achievement for the Electronic-Acquisition Software's system. Potential examinations is possible for building up the model in a way through including different factors which are not employ in current model, for example, utilizing the develops of the innovation acknowledgment 
framework (T.A.M.). This will be fascinating for building degree included comparative report through attracting answerer who are provider for products/administrations, yet additionally acquirement councils of merchandise/administrations, and draw an examination between the two gatherings of respondents.

\section{ACKNOWLEDGEMENTS}

I am gratefully thank the Chairman of K.U.B.S., Dr. Muhammad Asim for supporting me in investigation and apportioning us with an agreeable Teacher (Mr. Salman Manzoor) for developing the paper.

\section{REFERENCES}

[1] Abu-Shanab, E. and Al-Azzam "Trust dimensions and the adoption of e-government in Jordan," International Journal of Information Communication Technologies and Human Development, vol. 4, No. 1, pp.39-51, year 2012.

[2] Agarwal, R. and Prasad, J. "Are individual differences germane to the acceptance of new information technologies," Decision Sciences, vol. 30, No. 2, pp.361-391, year 1999.

[3] Aladwani, A.M. "A contingency model of citizens attitudes toward e-government use," Electronic Government, an International Journal, vol. 10, No. 1, pp.68-85, year 2013.

4] Al-Bakri, A.A., Cater-Steel, A. and Soar, J. "The influence of B2B e-commerce on SMEs' performance and efficiency: a review of the literature," International Journal of Liability and Scientific Enquiry, vol. 3, No. 3, pp.213-224, year 2010.

[5] Al-Gahtani, S.S. and King, M. "Attitudes, satisfaction and usage: factors contributing to each in the acceptance of information technology," Behaviour and Information Technology, Vol. 18, No. 4, pp.277-297, year 1999.

[6] Anderson, J.C. and Gerbing, D.W. "The effect of sampling error on convergence, improper solutions, and goodness-of-fit indices for maximum likelihood confirmatory factor analysis," Psychometrika, vol. 49, No. 2, pp.155-173, year 1984.

[7] Armstrong-Stassen, M., Cameron, S.J., Mantler, J. and Horsburgh, M.E. "The impact of hospital amalgamation on the job attitudes of nurses," Canadian Journal of Administrative Sciences/Revue Canadienne des Sciences de l'Administration, vol. 18, No. 3, pp.149-162, year 2001.

[8] Bailey, J.E. and Pearson, S.W. "Development of a tool for measuring and analyzing computer user satisfaction," Management Science," vol. 29, No. 5, pp.530-545, year 1983.

[9] Belanche, D., Casaló, L.V. and Guinalíu, M. "How to make online public services trustworthy," Electronic Government, an International Journal, vol. 9, No. 3, pp.291-308, year 2012

[10] Belanche, D., Casaló, L.V., Flavián, C. and Schepers, J. "Trust transfer in the continued usage of public e-services," Information and Management, vol. 51, No. 6, pp.627-640, year 2014.

[11] Belanger, F., Hiller, J.S. and Smith, W.J. "Trustworthiness in electronic commerce: the role of privacy, security, and site attributes," The Journal of strategic Information Systems, vol. 11, No. 3,pp.245-270, year 2002.

[12] Bernroider, E.W. and Schmollerl, P. "A technological, organisational', and environment analysis of decision making methodologies and satisfaction in the context of IT induced business," European Journal of Operational Research, vol. 224, No. 1, pp.141-153, year 2013.
[13] Budiardjo, E.K., Pamenan, G., Hidayanto, A.N., Meyliana, D. and Cofriyanti, E. "The impact of knowledge management system quality on the usage continuity and recommendation intention," Knowledge Management and E-Learning: An International Journal (KM\&EL), vol. 9, No. 2, pp.200-224, year 2017.

[14] Burke, R.R. "Technology and the customer interface: what consumers want in the physical and virtual store," Journal of the Academy of Marketing Science, Vol. 30, No. 4, pp.411-432, year 2002.

[15] Chatzopoulos, K.C. and Economides, A.A. "A holistic evaluation of Greek municipalities' websites," Electronic Government, an International Journal, vol. 6, No. 2, pp.193-212, year 2009.

[16] Choi, H., Park, M.J., Rho, J.J. and Zo, H. "Rethinking the assessmentF of e-government implementation in developing countries from the perspective of the design-reality gap: Applications in the Indonesian Electronic-Acquisition Software's system," Telecommunications Policy, vol. 40, No. 7, pp.644-660, year 2016

[17] Chong, B., Yang, Z. and Wong, M. "Asymmetrical impact of trustworthiness attributes on trust, perceived value and purchase intention: a conceptual framework for cross-cultural study on consumer perception of online auction," Proceedings of the 5th International Conference on Electronic Commerce, Association of Computing Machinery Press,pp.213-219, year 2003.

[18] Creswell, J.W. "Research Design: Qualitative, Quantitative and Mixed Methods Approaches," Sage Publications, Thousand Oaks, California, year 2003.

[19] Croom, S. and Brandon-Jones, A. "Impact of ElectronicAcquisition: Experiences from implementation in the UK public sector," Journal of Purchasing and Supply Management, vol. 13, No. 4,pp.294-303, year 2007.

[20] Davis, F.D. "Perceived usefulness, perceived ease of use, and user acceptance of information technology," MIS Quarterly, vol. 13, No. 1,pp.319-340, year 1989.

[21] DeLone, W.H. and McLean, E.R. "Information systems success: the quest for the dependent variables," Information Systems Research, vol. 3, No. 1, pp.60-95, year 1992.

[22] DeLone, W.H. and McLean, E.R. "The DeLone and McLean model of information systems success: a ten-year update," Journal of Management Information Systems, vol. 19, No. 4, pp.9-30, year 2003.

[23] Detiknas "Electronic-Acquisition," Retrieved from http://www.detiknas.org.

[24] European Bank, "Are you Ready for e-Procurement?," Guide to Electronic Procurement Reform, year 2015"

[25] Gemoets, L.A., Mahmood, M.A., Adenso-Diaz, B. and Gonzalez, P., "A cross-national comparison of e-government success measures: a theory-based empirical research', International Journal of Electronic Governance, vol. 4, No. 3, pp.184-208, year 2011 .

[26] Ghozali, I., "Structural Equation Modeling-Teori, Konsep, Dan AplikasiDengan Program LISREL 8.80," Universitas Diponegoro, Semarang, Indonesia, year 2008

[27] Gil-Garcia, J.R. and Sayogo, D.S., "Government interorganizational information sharing initiatives: Understanding the main determinants of success," Government Information Quarterly, Press, Available online $17^{\text {th }}$ February, year 2016.

[28] Gracia, D.B. and Ariño, L.V.C., "Rebuilding public trust in government administrations through e-government actions," Revista Española de Investigación en Marketing ESIC, vol. 19, 
No. 1,pp.1-11, year 2015.

[29] Gupta, M. and Narain, R., "A survey on adoption of ElectronicAcquisition Software's Software's in Indian organizations," International Journal of Indian Culture and Business Management, vol. 5, No. 1, pp.76-109, year 2011.

[30] Harold, L. and Thenmozhi, M., "Information quality and banking success: a theoretical model with empirical validation', International Journal of Information Quality, vol. 3, No. 3, pp.251-272, year 2014.

[31] Hidayanto, A.N., Ditari, Y. and Chahyati, D., "Study of Electronic-Acquisition Software's implementation impacts: a case study in PT. PLN," IEEE International Conference on Management of Innovation and Technology (ICMIT), Bali, pp.152-157, year 2012.

[32] Hidayanto, A.N., Limupa, A., Junus, K.M. and Budi, N.F.A., "Investigating knowledge sharing behaviour on virtual community members: integration of technological, individual and contextual factors," International Journal of Business Information Systems, Vol. 19, No. 2, pp.180-204, year 2015.

[33] Hsu, C-L., Chen, M-C., Kikuchi, K. and Machida, I., "Elucidating the determinants of purchase intention toward social shopping sites: a comparative study of Taiwan and Japan," Telematics and Informatics, Vol. 34, No. 4, pp.326-338, year 2017.

[34] Iacobucci, D., "Structural equations modeling: Fit Indices, sample size and advanced topics," year 2009.

[35] Journal of Consumer Psychology, vol. 20, No. 1, pp.90-98.

[36] Indonesia's Country Procurement Assessment Report, Indonesia Country Procurement Assessment Report-Reforming the Public Procurement System, World Bank, 4 April, year 2013.

[37] Johnson, B. and Christensen, L., Education Research: Quantitative, Qualitative and Mixed Approaches, Sage Publications, Thousand Oaks, California, year 2008.

[38] Kamarulzaman, N.H. and Mohamed, Z., "Application of Electronic-Acquisition Software's technologies for selecting users of agro-based SMEs in Malaysia," Int. Journal of Economics and Management, vol. 7, No. 1, pp.45-66, year 2013.

[39] Kumar, R.., Research Methodology: A Step-By-Step Guide for Beginners, Sage Publications, Thousand Oaks, California.

[40] Kumaralalita, L., Hidayanto, A.N. and Anggunia, S.D., "The impact of Electronic-Acquisition Software's Software's to accountability using theoretical frameworks on a case study," Technology Innovation and Industrial Management (TIIM) International Conference, year 2014.

[41] Lean, O.K., Zailani, S., Ramayah, T. and Fernando, Y., "Factors influencing intention to use e-government services among citizens in Malaysia," International Journal of Information Management, vol. 29, No. 6, pp.458-475, year 2009.

[42] Lee, J., Kim, H.J. and Ahn, M.J., "The willingness of eGovernment service adoption by business users: The role of offline service quality and trust in technology," Government Information Quarterly, vol. 28, No. 2,pp.222-230, year 2011.

[43] Liao, S-H., Cheng, C-H., Liao, W-B.and Chen, I-L., "A webbased architecture for implementing electronic procurement in military organisations," Technovation, vol. 23, No. 6, pp.521-532, year 2003 .

[44] Lin, H-F., "Measuring online learning systems success: applying the updated DeLone and McLean model," Cyberpsychology and Behavior, vol. 10, No. 6, pp.817-820, year 2007.
[45] Lin, H-H.and Wang, Y-S., "An examination of the determinants of customer loyalty in mobile commerce contexts," Information and Management, vol. 43, No. 3, pp.271-282, year 2006.

[46] Ling, K.C., Chai, L.T. and Piew, T.H., "The effects of shopping orientations, online trust and prior online purchase experience toward customer's online purchase intention," International Business Research, vol. 3, No. 2, pp.63-76, year 2010.

[47] Mathwick, C., Malhotra, N. and Rigdon, E., "Experiential value: conceptualization, measurement and application in the catalog and Internet shopping environment," Journal of Retailing, vol. 77, No. 1, pp.39-56, year 2011.

[48] Molla, A. and Licker, P.S., "E-commerce systems success: an attempt to extend and respecify the Delone and Mclean model of IS Success," Journal of Electronic Commerce Research, vol. 2, No. 4,pp.131-141, year 2001.

[49] Mose, J.M., Njihia, J.M. and Magutu, P.O., "The critical success factors and challenges in Electronic-Acquisition Software's adoption among large scale manufacturing firms in Nairobi', Kenya," European Scientific Journal, vol. 9, No. 13, pp.375-401, year 2013.

[50] Ndou, V., "E-government for developing countries: opportunities and challenges," The Electronic Journal of Information Systems in Developing Countries, vol. 18, No. 1, pp.1-24, year 2004.

[51] Nulhusna, R., Sandhyaduhita, P.I., Hidayanto, A.N. and Phusavat, $\mathrm{K}$., "The relation of e-government quality on public trust and its impact on public participation," Transforming Government: People, Process and Policy, vol. 11, No. 3, pp.393-418, year 2017.

[52] Papadomichelaki, X. and Mentzas, G., "Analysing e-government service quality in Greece," year 2011.

[53] Electronic Government, an International Journal, vol. 8, No. 4, pp.290-308.

[54] Parasuraman, A. and Zinkhan, G.M., "Marketing to and serving customers through the Internet: an overview and research agenda," Journal of the Academy of Marketing Science, vol. 30, No. 4,pp.286-295, year 2002.

[55] Prattipati, S.N., "Adoption of e-Government: differences between countries in the use of online government service," Journal of American Academy of Business, Vol. 3, Nos. 1-2, pp.386-391, year 2003.

[56] Rahim, M.M. and As-Saber, S.N., "Electronic-Acquisition Software's adoption process: an arduous journey for an Australian city council', International Journal of Electronic Finance, vol. 5, No. 2, pp.150-168, year 2011.

[57] Rai, A., Lang, S.S. and Welker, R.B., "Assessing the validity of IS success models: an empirical test and theoretical analysis," Information Systems Research, vol. 13, No. 1, pp.5069, year 2011.

[58] Ravi, S.P., "Innovation with information technology: coalition governments and emerging economies-fighting corruption with electronic governance," International Journal of Business and Emerging Markets, vol. 5, No. 1, pp.46-66, year 2013.

[59] Rhoades, L. and Eisenberger, R, "Perceived organizational support: a review of the literature," Journal of Applied Psychology, Vol. 87, No. 4, pp.698-714, year 2002.

[60] Ristig, K., "The impact of perceived organizational support and trustworthiness on trust," year 2009.

[61] Management Research News, vol. 32, No. 7, pp.659-669. 
[62] Seckler, V., "Survey says Web apparel buys doubled', Women Wear Daily, p.2, $12^{\text {th }}$ July, year 2000.

[63] Seddon, P.B., "A respecification and extension of the DeLone and McLean model of IS success," Information Systems Research, vol. 8, No. 3, pp.240-253, year 1997.

[64] Senn, J., "Business-to-business e-commerce," Information Systems Management,vol. 7, No. 2,pp.57-63, year 2000.

[65] Seo, D. and Warman, G., "User satisfaction of e-government procurement systems in developing countries: an empirical research in Indonesia," Thirty Second International Conference on Information Systems, Shanghai, China, year 2011.

[66] Sharma, S.K., "Adoption of e-government services: The role of service quality dimensions and demographic variables," Transforming Government: People, Process and Policy, Vol. 9, No. 2, pp.207-222, year 2015.

[67] Shih, P-C., Munoz, D. and Sanchez, F., "The effect of previous experience with information and communication technologies on performance in a web-based learning program," Computers in Human Behavior, Vol. 22, No. 6,pp.962-970, year 2006.

[68] Sirdeshmukh, D., Singh, J. and Sabol, B., "Consumer trust, value, and loyalty in relational exchanges," Journal of Marketing, Vol. 66, No. 1,pp.15-37, year 2002.

[69] Siriluck, R., "Critical governance concerns of Thailand egovernment procurement', International Conference on Information Resources Management (CONF-IRM) - 2012 Proceedings, AIS Electronic Library, p.52, year 2012.

[70] Tapscott, D. and Capson, A., Paradigm Shift: The New Promise of Information Technology, McGraw-Hill, Ohio, year 1993.

[71] Tat-Kei Ho, A., "Reinventing local governments and the egovernment initiative," Public Administration Review, Vol. 62, No. 4, pp.434-444., year 2002.

[72] Tatsis, V., Mena, C., Wassenhove, L.N. and Whicker, L., "Electronic-Acquisition Software's in the Greek food and drink industry: drivers and impediments," Journal of Purchasing and Supply Management, Vol. 12, No. 2, pp.63-74, year 2006.

[73] Thatcher, J., McKnight, D.H. and Ahuja, M., "The work environment and technology acceptance: The influence of affective commitment, autonomy and trust," Information Systems Technical Reports and Working Papers, year 2002.

[74] Tornatzky, L. and Fleischer, M., The Processes of Technological Innovation, Lexington Books, Lexington, year 1990.

[75] UN-ESCAP, ADBI and PPS., Economic and Social CommI.S'sion for Asia and The Pacific Asian Development Bank Institute Public Procurement Service of The Republic of Korea, $4^{\text {th }}$ April,year,2013. www.unescap.org/idd/Pubs/st_escap_2406.pdf

[76] Vathanophas, V., Krittayaphongphun, N. and Klomsiri, C., "Technology acceptance toward e-government initiative in Royal Thai Navy," Transforming Government: People, Process and Policy, vol. 2, No. 4, pp.256-282, year 2008.

[77] Venkatesh, V. and Davis, F.D., "A theoretical extension of the technology acceptance model: four longitudinal field studies," Management Science, vol. 46, No. 2, pp.186-204, year 2000.

[78] Wang, Y-S., “Assessing e-commerce systems success: a respecification and validation of the DeLone and McLean model of IS success," Information Systems Journal, vol. 18, No. 5, pp.529-557, year 2008.

[79] Wang, Y-S.and Liao, Y-W., "Assessing e-Government systems success: a validation of the DeLone and McLean model of information systems success," Government Information Quarterly, vol. 25, pp.717-733, year 2008.

[80] Wijanto, S.H., Structural Equation Modeling dengan LISREL 8.80 - Konsepdan Tutorial, GrahaIlmu, Yogyakarta, year 2008

[81] Wilson, P. and Rodgers, W., "The relationship between perceived autonomy support, exercise regulations and behavioral intentions in women," Psychology of Sport and Exercise, Vol. 5, No. 3, pp.229-242, year 2004.

[82] Zhou, T., "An empirical examination of initial trust in mobile banking," Internet Research, Vol. 21, No. 5, pp.527-540, year 2011 .

[83] Zhu, K., Xu, S. and Dedrick, J., "Assessing drivers of E-Business value: results of a cross country study," Twenty-Fourth International Conference on Information Systems, Seattle, Washington, pp.1-13, year 2003. 